\title{
La persona con discapacidad y su protección jurídica en época de pandemia en Colombia
}

\author{
Recibido: 31 de julio de 2020 • Aprobado: 12 de septiembre de 2020 \\ https://doi.org/10.22395/ojum.v20n42a8
}

\author{
Diana Carolina Camargo Farías \\ Fundación Universitaria Juan de Castellanos, Tunja, Colombia \\ dcamargo@jdc.edu.co \\ https://orcid.org/0000-0003-3049-0525 \\ Sergio Andrés López-Zamora \\ Fundación Universitaria Juan de Castellanos, Tunja, Colombia \\ salopez@jdc.edu.co \\ https://orcid.org/0000-0003-1350-6310
}

\section{RESUMEN}

Este artículo expone un análisis, desde una perspectiva jurídica, del estado de protección de la persona con discapacidad en Colombia a partir de la declaratoria del estado de emergencia económica, social y ecológica en el territorio nacional ante la propagación de la Covid-19. En este sentido, se generan recomendaciones que aseguren una protección jurídica en el territorio colombiano. El desarrollo del artículo expone la situación de las personas con discapacidad durante la pandemia. Se analizan las medidas de protección jurídica dispuestas por el Gobierno y las recomendaciones surgen como pertinentes para una protección jurídica efectiva. El abordaje planteado se sustenta a partir de una metodología dogmática del tipo básico-jurídica, pues el objeto de estudio está constituido por la normatividad colombiana en materia de discapacidad que surge a partir de la declaratoria de emergencia en territorio nacional. Además, se utilizan fuentes secundarias de investigación y se analizan la ley y la doctrina aplicable al objeto de estudio. Con lo anterior se mostrará que, en época de pandemia, el Estado colombiano ha intentado ajustarse a los lineamientos de la ONU para propender por mantener la garantía de los derechos de manera equitativa y justa. No obstante, surgen algunas recomendaciones precisas y ajustadas que sugerimos para alcanzar dichos fines y porque resultan pertinentes al discurso garantista hoy existente.

Palabras clave: protección estatal; persona con discapacidad; Covid-19; inclusión; pandemia. 


\section{People with Disabilities and their Legal Protection in a Time of Pandemic in Colombia}

\section{ABSTRACT}

This article presents an analysis, from a legal perspective, of the protection status of persons with disabilities in Colombia based on the declaration of the State of Economic, Social and Ecological Emergency in the national territory in the face of the spread of Covid-19, generating recommendations that ensure legal protection in the Colombian territory. The development of the article lays out the situation of people with disabilities during the pandemic, what are the legal protection measures ordered by the government and what recommendations emerge as relevant for effective legal protection. The proposed approach is based on a dogmatic methodology of the basic-legal type, since the object of study is constituted by the Colombian regulations on disability that arises from the declaration of Emergency in national territory, using secondary sources of research, analyzing the law and doctrine applicable to the object of study. With the aforementioned, it will be shown that in times of pandemic the Colombian State has tried to adjust to the UN guidelines, aiming to maintain the guarantee of rights in an equitable and fair manner, however, some precise recommendations are made, which are pertinent in the context of the current guarantees discourse. Keywords: State protection; disabled person; Covid-19; inclusion; pandemic. 


\section{INTRODUCCIÓN}

El presente artículo proviene del proyecto de investigación titulado Estado de realización de los derechos de las personas con discapacidad y su vinculación con la política pública en siete municipios de la provincia centro del departamento de Boyacá, cuya finalización se encuentra programada para el semestre 2020-II y está financiado por la Fundación Universitaria Juan de Castellanos. Los autores son coinvestigadores vinculados al proyecto adscrito al Grupo de Investigación Hugo Grocio de dicha institución.

Se trata de una investigación dogmática del tipo básico-jurídica, pues el objeto de estudio está constituido por la normatividad colombiana en materia de discapacidad que surge a partir de la declaratoria de emergencia en territorio nacional. Para el efecto, se utilizaron fuentes secundarias de investigación, y se analizó la ley y la doctrina aplicable al objeto de estudio.

Sobre este contexto, el artículo responde a la siguiente pregunta: ¿Cuál es el estado de protección jurídica de la persona con discapacidad en época de pandemia en Colombia? Esta pregunta surge del objetivo general de determinar el estado de protección jurídica de la persona con discapacidad en época de pandemia en Colombia.

Por objetivos específicos, se postularon los siguientes: i) indagar la situación de la persona con discapacidad durante la pandemia Covid-19 en Colombia; ii) analizar las medidas de protección jurídica de la persona con discapacidad en época de pandemia; y iii) establecer recomendaciones para la protección jurídica de la persona con discapacidad en época de pandemia.

Por lo anterior, fue empleado un método deductivo de investigación, pues se hizo un análisis de conceptos y normas internacionales generales, para culminar en la normatividad colombiana en particular, con el fin de indagar sobre el estado de protección jurídica de la persona con discapacidad en territorio colombiano.

\section{CONTEXTO}

El secretario general de las Naciones Unidas, António Guterres (Organización de las Naciones Unidas, 2020, pár. 20-22), recordó la importancia de acentuar la protección de las personas con discapacidad a partir de la intensificación en la propagación de la Covid-19. Entre otros, se recordó las altas tasas de mortalidad en hogares de ancianos, así como el mayor riesgo de pérdida de empleo, de violencia doméstica y la necesidad de asegurar los derechos y promover la inclusión.

Este llamado a la conciencia y a la humanidad, más que ser un detonante para la protección de las personas con discapacidad, debió ser un recordatorio de algo que los Estados ya deberían estar ejecutando precisamente en búsqueda de una igualdad material que sea garante de derechos. 
Es así que de manera previa al estudio de la persona con discapacidad, se hace necesario recordar que desde el 31 de diciembre de 2019, el municipio de Wuhan (provincia de Hubei en China) dio a conocer algunos casos de neumonía con etiología desconocida (Organización Panamericana de la Salud [OPS], 2020).

Un mes después y ya habiendo casi diez mil casos confirmados en China y ciento seis confirmados en ciento nueve países, el director general de la Organización Mundial de la Salud declara que el brote representaba una emergencia de salud pública con relevancia internacional (OPS, 2020).

El brote epidemiológico llega oficialmente a Colombia el 6 de marzo de 2020 cuando se reporta el primer caso en el territorio. Se trató de una mujer de diecinueve años proveniente de Milán, Italia (Instituto Nacional de Salud [INA], 2020). El virus empieza a propagarse por las ciudades más grandes del país hasta que el 17 de marzo —entonces con ciento cincuenta y siete casos positivos - el Estado colombiano promulga el Decreto 417 (2020) con el que declara el estado de emergencia económica, social y ecológica en el territorio nacional.

El estado de emergencia es decretado por la Presidencia de la República en uso del artículo 215 de la Constitución Política de Colombia (1991), por sobrevenir una situación que daña o pone en peligro en forma grave e inminente el orden económico, social y ecológico del país o que constituya grave calamidad pública, bajo el fin de conjurar la crisis e impedir la extensión de sus efectos.

Así, en el contexto del estado de emergencia decretado, era de esperar medidas que garantizaran la estabilidad de los derechos de toda persona en territorio colombiano, pero con más fuerza para las personas con discapacidad. En este sentido, se recuerda la pretensión material del derecho constitucional de la necesidad de que la humanidad entera pueda subsistir dentro condiciones materiales que generen posibilidades para seguir haciéndolo (Seco, 2015, p 1).

Por lo anterior, entraremos a estudiar a la persona con discapacidad en el contexto del estado de emergencia decretado en respuesta de la propagación de la Covid-19 en territorio colombiano, lo cual servirá de resorte para determinar su protección jurídica y posibles recomendaciones en época de pandemia.

\section{LA SITUACIÓN DE LA PERSONA CON DISCAPACIDAD DURANTE LA PANDEMIA POR LA COVID-19}

Como reconocen Gómez et al. (2018), la discapacidad es un concepto dinámico y evolutivo que a lo largo del tiempo ha sido definido a partir de diferentes modelos, en lo que predomina el médico y el social. El primero entiende que la discapacidad responde a limitantes biológicos y promulga por su rehabilitación. Por otro lado, el segundo asume a la discapacidad como una respuesta de la interacción entre el sujeto y el ambiente en que se desarrolla con la pretensión de atenuar las desventajas de la persona en relación con la sociedad a la que pertenece. 
El modelo social — con tendencia en Colombia - genera acciones positivas e incluyentes que han llevado a importantes avances, como el deber de sustraer de la persona con discapacidad visiones de caridad, de pacientes o de sujetos con déficits individuales (Congreso Europeo sobre las Personas con Discapacidad, 2002). Sin embargo, se mantuvo el manejo de otros términos peyorativos, como la expresión "discapacitado" o "persona con capacidades diferentes" — vocablos restringidos por generar una imagen distorsionada que elimina rasgos de individualidad y las percibe solo en relación con la discapacidad de la persona — que poco a poco han menguado.

Así, autoridades como la Asociación Síndrome de Down de la República Argentina (s.f., pár. 5) han concluido que expresiones como "persona con discapacidad" han surgido del modelo social que ubica en primer término a la persona, y a la discapacidad como una más de sus características. De esta manera, se entiende que la discapacidad se define tras la relación del sujeto con las barreras de su entorno. Lo importante de esta terminología es que resultó adaptada a la Convención Internacional sobre los Derechos de las Personas con Discapacidad como sugerencia formulada por personas con discapacidad (Organización de las Naciones Unidas, 2006, p. 14).

Fue precisamente dentro del modelo social que autores como Kenneth (2005) propusieron un concepto universal de la discapacidad, por la cual toda persona está en condición de riesgo, dado que es una condición que podrá presentarse en cualquier momento de la vida de la persona. Este criterio lo recoge el Informe mundial sobre la discapacidad de la Organización Mundial de la Salud (OMS, 2011) cuando concluye que toda persona tendrá una discapacidad en algún momento de su existencia y que se verá acentuada durante la vejez.

En el mismo informe fue estimado que más de mil millones de personas vivían a la fecha con alguna clase de discapacidad —alrededor del $15 \%$ de la población mundial- (OMS, 2011). Esta cifra ha venido aumentando paulatinamente y se espera crecimiento. Este hecho ha motivado otros avances, como la Convención sobre los Derechos de las Personas con Discapacidad aprobada por la Asamblea General de las Naciones Unidas (2006) el 13 de diciembre (ratificada por Colombia en el año 2011), con el fin de permitir a los Estados parte la viabilidad de marcos normativos internos que garanticen su cumplimiento y, en general, una protección eficaz de la persona con discapacidad.

Esto también desembocó en que, en septiembre de 2015, los Estados miembros de la ONU firmaran los objetivos del desarrollo sostenible 2015-2030, donde concretamente los objetivos 10 y 16 - enfocados en la discapacidad - sostienen la intención de disminuir desigualdades para garantizar "que nadie se queda atrás" y la meta de promover sociedades pacíficas e inclusivas que faciliten el acceso a la justicia, con instituciones eficaces, responsables e inclusivas para todos (Organización de las Naciones Unidas [ONU], 2015). 
Este contexto, en materia de salud, había sido recogido por la Convención Internacional Sobre los Derechos de las Personas con Discapacidad (ONU, 2006), entendido como derecho de irrestricto cumplimiento para los Estados parte. En esta convención se exige un reconocimiento sin discriminación por motivos de discapacidad y un acceso a los servicios de salud del más alto nivel, sin tener en cuenta cuestiones de género, incluida la rehabilitación relacionada con la salud.

La Convención da lugar en Colombia a la Ley Estatutaria 1618 (2013) por la cual se establecen disposiciones para garantizar el pleno ejercicio de los derechos de las personas con discapacidad. Esta ley concibe un acceso a la atención de la salud, prevención de la enfermedad, detección temprana, diagnóstico, tratamiento, rehabilitación y paliación. Además, generó normas como la Ley 1751 (2015) que establece a la persona con discapacidad como sujeto de especial protección constitucional por parte del Estado y lo obliga a que las instituciones que pertenezcan al sector de la salud definan procesos intersectoriales e interdisciplinarios que garanticen las mejores condiciones de atención.

Lo anterior recoge la tutela de la persona con discapacidad del modelo social colombiano que, atendiendo las sugerencias del secretario general de las Naciones Unidas - António Guterres- de acentuar la protección de las personas con discapacidad a partir de la intensificación en la propagación de la enfermedad coronavirus (Organización de las Naciones Unidas, 2020, pár. 20-22), motivó la promulgación de los lineamientos de prevención del contagio por la Covid-19 y atención en salud para las personas con discapacidad, sus familias, las personas cuidadoras y actores del sector salud, con el objeto de orientar en la implementación de medidas diferenciales de prevención y mitigación del contagio del virus y la atención en salud (Ministerio de Salud y Protección Social [MSPS], 2020, p. 5).

El contenido de los lineamientos mantiene un esquema didáctico que parte de nociones generales de discapacidad y recuerda las siete clases reconocidas en Colombia, a saber, discapacidad física, discapacidad auditiva, discapacidad visual, sordoceguera, discapacidad intelectual, discapacidad psicosocial (mental) y discapacidad múltiple (Ministerio de Salud y Protección Social, 2020, pp. 5-9).

En una segunda sección, se establecen orientaciones generales para la prevención del contagio en las personas con discapacidad, sus familias y personas cuidadoras. Además, se exalta la importancia en la promoción y atención de la salud mental y se delimitan las medidas para la limpieza y desinfección del entorno hogar, así como las directrices en caso de existir riesgo razonable de contagio (Ministerio de Salud y Protección Social, 2020, pp. 10-17).

En este sentido, no se puede ignorar que la novedad de la Covid-19 ha sometido a la investigación científica a trabajar sobre la marcha, por lo que no existen datos 
sobre la situación de discapacidad en el caso de personas enfermas ni en el de las personas fallecidas. Sin embargo, existe una relación entre edad y discapacidad, por lo que es razonable pensar que algunas de las personas mayores que padecen el virus o fallecieron por esta causa tenían alguna discapacidad (Comisión Económica para América Latina y el Caribe [Cepal], 2020, p. 2), lo cual responde a la prevención inmersa en estos lineamientos.

En el mismo sentido, el Ministerio de Salud y Protección Social (2020, p. 18) señala por directriz que toda información referente a las medidas de prevención y autocuidado para la prevención del contagio debe ser presentada en formatos accesibles, con un lenguaje claro, interpretación en lengua de señas, subtitulación, información en audio y canales de atención con medios alternos como chat, con lo que se garantiza una comunicación inclusiva.

En este contexto se reconoce que, además de su perfil etario, las personas con discapacidad tienen un mayor riesgo ante la Covid-19 debido a sus limitadas posibilidades de protegerse del contagio o de buscar diagnóstico y tratamiento por la poca información sobre el virus en formatos accesibles y la falta de accesibilidad en los establecimientos de salud (Comisión Económica para América Latina y el Caribe [Cepal], 2020, p. 2).

Igualmente, los lineamientos contienen medidas de prevención para los actores del sector salud con acciones en el ámbito comunitario (Ministerio de Salud y Protección Social, 2020, pp. 19-20), donde se obliga a implementar medidas tendientes a la prevención del contagio y al acatamiento de las medidas de confinamiento obligatorio a partir de la generación de mecanismos no presenciales de comunicación para mitigar el contagio.

En este contexto particular, se recuerda que el confinamiento físico aplicado en países de la región para frenar la transmisión del virus constituye otro riesgo de vulneración, lo cual resulta especialmente crítico en el caso del servicio de salud, rehabilitación y cuidados en general, así como en el acceso de medicamentos, pañales, dispositivos de asistencia, alimentos especiales e insumos equivalentes debido a la dificultad en su acceso. Asimismo, se ha entendido que se trata de una medida que puede agravar ciertos tipos de discapacidad que requieren de actividad física para su tratamiento, como las personas con trastorno del espectro autista (TEA), cuyas rutinas permiten atenuar el estrés y la ansiedad (Cepal, 2020, p. 3).

Por su parte, los lineamientos también señalan medidas de prevención en el entorno institucional relacionadas con la intensificación de medidas de limpieza y desinfección teniendo en cuenta usuarios que usan silla de ruedas y condiciones análogas de discapacidad (como muletas, bastones, audífonos, amplificadores, pantallas, señales braille y alto relieve, entre otros), así como el acceso de insumos como jabón 
o gel antibacterial al alcance de niños, personas usuarias de silla de ruedas y de las personas de talla baja (Ministerio de Salud y Protección Social, 2020, p. 21).

Asimismo, los lineamientos contienen orientaciones generales para la atención en salud de las personas con discapacidad, sus familias y cuidadores en el marco de la emergencia sanitaria (Ministerio de Salud y Protección Social, 2020, pp. 21-22), y orientaciones en atención a la discapacidad específica que presenta la persona (Ministerio de Salud y Protección Social, 2020, pp. 22-24). Se hace una clasificación entre personas con discapacidad visual (individualizando casos donde se cuente con perro guía), personas que interactúan con discapacidad visual en su entorno hogar o laboral, personas con discapacidad auditiva y personas con discapacidad intelectual que requieren apoyos para la comprensión de mensajes.

Finalmente, se relacionan medidas para los centros dedicados al cuidado de la persona con discapacidad (Ministerio de Salud y Protección Social, 2020, pp. 24-27) con directrices para residentes asintomáticos, para casos de riesgo de contagio y para contagiados con discapacidad.

Esto se debe a que las personas con discapacidad, ubicadas en instituciones y residencias comunitarias, son especialmente vulnerables a la Covid-19 a causa de las limitadas opciones de distanciamiento social y las condiciones físicas en estos establecimientos (Cepal, 2020, p. 2).

En suma, se tiene que las directrices del Ministerio de Salud y Protección Social (2020) han comprendido el interés señalado por la Organización de las Naciones Unidas, cuyos lineamientos muestran acciones específicas de inclusión que responden a la situación actual. Se recuerda que a la fecha de redacción de este artículo ya se ha llegado a los 2.114 .597 contagios y a las 54.576 muertes en el país al 2 de febrero de 2021 (Ministerio de Salud y Protección Social, 2021, pár. 2).

De acuerdo con lo expuesto, es claro que Colombia se ha adaptado a un modelo social que entiende a la persona con discapacidad como un sujeto de especial protección al que ha envuelto de una tutela acentuada mediante los lineamientos diseñados por el Ministerio de Salud y Protección Social (2020), por lo que ahora habrá posibilidad de medir si resulta equivalente a la protección jurídica en época de pandemia.

\section{LAS MEDIDAS DE PROTECCIÓN JURÍDICA DE LA PERSONA CON DISCAPACIDAD EN ÉPOCA DE PANDEMIA}

Una vez contextualizados en la situación a la que ha traído la Covid-19 a la persona con discapacidad, se dará cabida a un análisis de las medidas de protección jurídica en época de pandemia. En primer lugar, se resalta que la Convención sobre los Derechos de las Personas con Discapacidad de Naciones Unidas (2006) establece en su artículo 11: 
Los Estados parte adoptarán, en virtud de las responsabilidades que les corresponden con arreglo al derecho internacional, y en concreto el derecho internacional humanitario y el derecho internacional de los derechos humanos, todas las medidas necesarias para garantizar la seguridad y la protección de las personas con discapacidad en situaciones de riesgo, incluidas situaciones de conflicto armado, emergencias humanitarias y desastres naturales.

De este modo y teniendo en cuenta que, como se refirió anteriormente, el director general de la Organización Mundial de la Salud (OMS), Tedros Adhanom Ghebreyesus, declaró en marzo del 2020 que el brote de la Covid-19, enfermedad causada por un nuevo coronavirus, pasaba de ser una epidemia a una pandemia en vista de la velocidad y la escala de la transmisión, es claro que se está ante una situación de riesgo para toda la humanidad, frente a la cual se requiere que los Estados tomen medidas urgentes y eficaces con el fin de contrarrestar las consecuencias de la Covid-19.

Así, a julio de 2020 se reportan en el mundo aproximadamente 12.232.211 personas contagiadas y aproximadamente 549.276 fallecidos (BBC, 2020). En el caso colombiano, de acuerdo con el Ministerio de Salud y Protección Social (2020), la cifra asciende los 248.976 casos confirmados y las 8.525 personas fallecidas.

Con ello, cabe mencionar aquí que, de conformidad con la Organización Panamericana de la Salud (2020, pp. 2-3), las personas con discapacidad pueden correr un riesgo mayor de contraer la Covid-19 debido a, entre otras cosas, factores como:

- Dificultades para implementar algunas medidas de higiene que resultan básicas como el lavado de las manos, pues en algunas ocasiones los lavamanos son físicamente inaccesibles para las personas con discapacidad.

- En el caso de las personas con discapacidad visual, por ejemplo, se encuentra la necesidad de apoyarse físicamente en estructuras de modo que puedan identificar el entorno.

- Obstáculos para acceder a información de salud pública en el sistema braille u otros formatos accesibles para los diferentes tipos de discapacidad como el visual, auditivo — con subtítulos-, entre otros.

- Si bien dentro del marco de la normalidad se ha manifestado que las personas con discapacidad tienen diferentes obstáculos (sociales, institucionales, estructurales, económicos) para acceder a la prestación del servicio de salud, la emergencia sanitaria ocasionada por la pandemia podría generar mayores obstáculos para el acceso a la atención de salud de este grupo poblacional.

En este contexto, desde la declaratoria de emergencia en el país, el Gobierno Nacional ha tomado diferentes medidas de orden económico, jurídico y social con el fin de contrarrestar las consecuencias de la Covid-19. Dentro de estas medidas y 
atendiendo a que la población con discapacidad es de las más afectadas por esta pandemia, en abril de 2020 el Gobierno informó:

En el marco de la emergencia generada por el coronavirus, el Gobierno nacional, a través de la Consejería Presidencial para la participación de personas con discapacidad, coordina acciones para atender a un total de 1.461 .524 hogares colombianos en donde al menos hay una persona en condición de discapacidad, de los cuales 1.026 .312 están registrados en el Sisbén (Decreto 417, 2020).

De la misma manera y específicamente desde el sector salud, se han tomado algunas medidas articuladas con los ministerios del Gobierno nacional en el marco de la pandemia, que han servido de fundamento jurídico para la toma de lineamientos y estrategias frente a la protección de la población con discapacidad. En este contexto, se relacionan a continuación algunas de las directrices emitidas por los ministerios de salud, interior e industria y comercio frente a la mitigación de las consecuencias de la Covid-19 (tabla 1).

Tabla 1. Directrices emitidas por el Ministerio de Salud y Protección Social en el marco de la Covid-19

\begin{tabular}{ll}
\hline \multicolumn{1}{c}{ Entidad } & \multicolumn{1}{c}{ Medida de protección jurídica } \\
\hline Ministerio de Salud y & Circular 05 (2020) \\
Protección Social & Dirigida a entidades territoriales \\
& y sus organismos de salud.
\end{tabular}

A través de esta circular, desde

el MSPS se establecen diferentes lineamientos institucionales para detectar, controlar y atender de manera celera la Covid-19.

\begin{tabular}{|c|c|c|}
\hline Ministerio de Salud y & Circular 011 (2020) & \\
\hline $\begin{array}{l}\text { Protección Social. } \\
\text { Ministerio de Comercio, } \\
\text { Industria Y Turismo. }\end{array}$ & $\begin{array}{l}\text { Dirigida a entidades territoriales } \\
\text { y organismos de salud. }\end{array}$ & $\begin{array}{l}\text { mendaciones para la conten- } \\
\text { ción de la Covid-19 en los } \\
\text { lugares de alta afluencia de } \\
\text { personas. }\end{array}$ \\
\hline Expedida conjuntamente & Circular 015 (2020) & Se incorporan medidas re- \\
\hline $\begin{array}{l}\text { por el Ministerio de Salud } \\
\text { y Protección Social y el } \\
\text { Ministerio del Interior }\end{array}$ & $\begin{array}{l}\text { Dirigida a secretarias de salud } \\
\text { del orden departamental, dis- } \\
\text { trital y municipal, entre otros. }\end{array}$ & $\begin{array}{l}\text { lacionadas con la Covid-19 y } \\
\text { ciertos grupos étnicos como lo } \\
\text { son los pueblos indígenas, las } \\
\text { comunidades negras, afroco- } \\
\text { lombianas, entre otros. }\end{array}$ \\
\hline
\end{tabular}




\begin{tabular}{|c|c|c|}
\hline Entidad & Medida de protección jurídica & Descripción \\
\hline Expedida conjuntamente & Circular 018 (2020) & A través de la cual se dictan \\
\hline $\begin{array}{l}\text { con el Ministerio Del } \\
\text { Trabajo y el Departamento } \\
\text { Administrativo de la Función } \\
\text { Pública }\end{array}$ & $\begin{array}{l}\text { Dirigida a organismos y en- } \\
\text { tidades del sector público y } \\
\text { privado, administradoras de } \\
\text { riesgos laborales, servidores } \\
\text { públicos, trabajadores del } \\
\text { sector privado, trabajadores } \\
\text { independientesy contratistas del } \\
\text { sector público y privado. }\end{array}$ & $\begin{array}{l}\text { acciones de contención ante } \\
\text { el Covid-19 y la prevención } \\
\text { de enfermedades asociadas } \\
\text { al primer pico epidemiológico } \\
\text { de enfermedades respiratorias. }\end{array}$ \\
\hline $\begin{array}{l}\text { Ministerio de Salud y Protección } \\
\text { Social }\end{array}$ & Resolución 380 (2020) & $\begin{array}{l}\text { Con esta resolución se adoptan } \\
\text { medidas preventivas sanitarias } \\
\text { para todo el territorio nacional. }\end{array}$ \\
\hline $\begin{array}{l}\text { Ministerio de Salud y Protección } \\
\text { Social }\end{array}$ & $\begin{array}{l}\text { Resolución } 385 \\
\text { (2020) }\end{array}$ & $\begin{array}{l}\text { A través de esta resolución, } \\
\text { el Gobierno nacional declara } \\
\text { emergencia sanitaria por cau- } \\
\text { sa de la Covid-19 y se adoptan } \\
\text { ciertas medidas para con- } \\
\text { trarrestar las consecuencias } \\
\text { del virus. }\end{array}$ \\
\hline $\begin{array}{l}\text { Ministerio de Salud y Protección } \\
\text { Social }\end{array}$ & Resolución 464 (2020) & $\begin{array}{l}\text { Se adoptan medidas relacio- } \\
\text { nadas específicamente con } \\
\text { los adultos mayores de setenta } \\
\text { años. }\end{array}$ \\
\hline $\begin{array}{l}\text { Ministerio De Salud Y Protección } \\
\text { Social }\end{array}$ & Resolución 470 de 2020 & $\begin{array}{l}\text { Se incorporan medidas sanitar- } \\
\text { ias obligatorias de } \\
\text { aislamiento preventivo de } \\
\text { personas adultas mayores } \\
\text { en centros de larga estancia, } \\
\text { centro de vida, entre otros. }\end{array}$ \\
\hline
\end{tabular}

Fuente: elaboración propia con datos obtenidos de las resoluciones mencionadas.

Con fundamento en las directrices anteriormente mencionadas, se reitera que el Ministerio de Salud y Protección Social (2020) emitió el documento titulado Lineamientos de prevención del contagio por la Covid-19 y atención en salud para las personas con discapacidad, sus familias, las personas cuidadoras y actores del sector salud con el objetivo de orientarlos en la implementación de medidas diferenciales de prevención y mitigación del contagio por la Covid-19 y la atención en salud.

Dentro de las principales recomendaciones emitidas por parte del MSPS para las personas con discapacidad durante la pandemia, se encuentran:

- Las personas con discapacidad, su cuidador(a) y su entorno familiar deberán reforzar las medidas de higiene, por ejemplo, a través del lavado constante de 
manos, desinfección (de la vivienda, del vehículo, etc.) y ventilación de los diferentes espacios dentro del hogar.

- Se recomienda limitar las visitas presenciales de personas que no hagan parte del núcleo familiar o que no habiten en el mismo domicilio.

- Fomentar los contactos virtuales entre las personas con discapacidad y sus familiares y cuidadores, de modo que se continúen fortaleciendo vínculos afectivos que atiendan, sobre todo, la posible afectación psicológica y emocional que se puede presentar debido al aislamiento estricto.

- Conformar redes de apoyo comunitario para realizar actividades como compras, pagos y gestión de citas médicas.

- Atendiendo a una de las limitaciones arriba referidas, se recomienda que toda la información ateniente a las medidas de prevención y autocuidado para la prevención del contagio debe ser presentada en formatos accesibles de acuerdo con el tipo de discapacidad (braille, subtítulos, lenguaje de señas).

- Se deberán aunar esfuerzos para que, especialmente durante la época de pandemia, se logre garantizar un acceso a la atención integral en salud sin barreras, esto incluye la accesibilidad comunicativa, física y actitudinal durante la atención.

- En el caso de las entidades prestadoras del servicio de salud es necesario que se garantice la atención priorizada a las personas con discapacidad que resulten contagiadas con la Covid-19, teniendo en cuenta su condición de salud.

Se resalta que, pese a que las medidas tomadas por el Gobierno nacional durante los últimos meses (desde el comienzo del aislamiento obligatorio) para la atención de la emergencia ocasionada por la Covid-19, ha sido numerosa (existen al menos 171 decretos a la fecha), son muy reducidas las relativas a la protección de las personas con discapacidad durante la época de pandemia.

En este contexto, Catalina Devandas, relatora especial sobre los derechos de personas con discapacidad de la ONU, afirmó:

Poco se ha hecho para proporcionar la orientación y los apoyos necesarios a las personas con discapacidad para protegerlas durante la actual pandemia del Covid-19, aun cuando muchas de ellas pertenecen al grupo de alto riesgo [...] Las personas con discapacidad sienten que las han dejado atrás, pues, las medidas de contención, como el distanciamiento social y el aislamiento personal, pueden ser imposibles para quienes requieren apoyo para comer, vestirse o ducharse $[\ldots]$ Este apoyo es básico para su supervivencia, y los Estados deben tomar medidas adicionales de protección social para garantizar la continuidad de los apoyos de una manera segura a lo largo de la crisis. (Oficina del Alto Comisionado de DDHHONU, 2020, pp. 3-6). 
De este modo, se recuerda que, de conformidad con la Convención sobre los Derechos de las Personas con Discapacidad, los Estados deben garantizar la integridad, protección, supervivencia y no discriminación de este grupo de personas durante épocas de crisis como la que actualmente se vive. Y es que la pandemia ha dejado a su paso graves consecuencias ligadas al ámbito sanitario (salud física y mental), laboral, escolar y económico, y ha afectado de manera especial a las personas con discapacidad. En este sentido, y para reafirmar la cita anterior, la Comisión Económica para América Latina y el Caribe (2020) abordó estos aspectos de la siguiente manera desde los ámbitos laboral, educativo, de salud y económico.

Ámbito laboral: si se tiene en cuenta que las personas con discapacidad ya tenían un tenue vínculo con el mercado laboral y una participación importante en el sector de servicios y en el empleo informal, es previsible que esta población se vea especialmente afectada por el desfavorable escenario del mercado laboral durante la crisis y el período de recuperación. Aunque los datos concretos sobre esta realidad escasean, en una investigación en el Paraguay se estimó que el 40 \% de las personas con discapacidad en ese país quedaron desempleadas tras el inicio de la cuarentena, con impactos significativos en los ingresos de sus hogares (Cepal, 2020, p. 3).

Cabe recalcar que, desde la jurisprudencia de la Corte Constitucional, se ha reiterado en diferentes providencias (Sentencia SU-040/18, 2018; Sentencia T-286/19, 2019; Sentencia T-340/17, 2017) que las personas en situación de discapacidad son sujetos de especial protección constitucional a los cuales se les debe garantizar, en materia laboral, los derechos a la estabilidad laboral reforzada y la permanencia o reubicación de personas que ven disminuida su capacidad laboral. Estos derechos, evidentemente, deberán tener un mayor grado de protección y garantía durante la época de pandemia.

Ámbito educativo: la interrupción de las actividades en centros educativos tendrá efectos significativos en el aprendizaje de estudiantes con discapacidad y podría afectar también su estado nutricional, ya que muchos estudiantes de hogares vulnerables, incluidos niños, niñas y adolescentes con discapacidad, dependen de programas de alimentación escolar. Aunque se han hecho planes para promover el uso de dispositivos digitales en los sistemas educativos, existen brechas en el acceso a las computadoras y a internet y limitaciones en las habilidades para su uso en los hogares con personas con discapacidad (Cepal, 2020, p. 5).

Ámbito de salud: el confinamiento y las restricciones de desplazamiento también pueden agravar la situación de personas con ciertos tipos de discapacidad, por ejemplo, aquellas con trastorno del espectro autista (TEA), cuyas rutinas permiten disminuir el estrés y la ansiedad. La interrupción de esas rutinas debido al confinamiento puede afectar de manera negativa el bienestar de esas personas y sus familias (Cepal, 2020, p. 7). 
Ámbito económico: el confinamiento físico que se ha aplicado en muchos países de la región para frenar la transmisión del virus puede interrumpir el acceso a bienes y servicios esenciales para que las personas con discapacidad puedan mantener su bienestar. Esto es especialmente crítico en el caso de servicios de salud, rehabilitación y cuidados, pero también en el de medicamentos, pañales, dispositivos de asistencia y alimentos especiales, entre otros insumos (Cepal, 2020, p. 3).

La anterior situación ha sido alertada por organismos internacionales como Human Rights Watch (2020) quienes han manifestado:

Las personas con discapacidad están entre las más marginadas y estigmatizadas del mundo, incluso en circunstancias normales, por ello, Si los gobiernos no toman medidas rápidas para incluir a las personas con discapacidad en su respuesta al Covid-19, seguirán expuestas a graves riesgos de contagio y muerte a medida que la pandemia se propague. (p. 10)

En este escenario, se debe mencionar que si bien a nivel nacional las medidas de protección y contención del virus en relación con las personas con discapacidad han girado prácticamente en torno a temas de salud, a nivel local se han implementado en algunas ciudades estrategias más amplias que podrían llegar a abarcar otros ámbitos relevantes para las personas con discapacidad durante esta época de pandemia.

De este modo, por ejemplo en Bogotá, desde el Sistema Distrital de Discapacidad, el Comité Técnico Distrital de Discapacidad y la Secretaría de Gobierno (2020), se han implementado las siguientes acciones:

- Con apoyo de las entidades administradoras de planes de beneficios se ha prestado el servicio de salud y rehabilitación domiciliaria.

- Asimismo, se han implementado herramientas como la asesoría telefónica y medios virtuales con el fin de promover y reforzar las medidas de prevención, cuidado y promoción de la salud para personas con discapacidad, cuidadores(as) y su entorno familiar.

- Desde los centros Renacer se han prestado servicios sociales de atención interna para personas con discapacidad.

- Se implementaron los bonos canjeables de apoyo alimentario para personas con discapacidad.

- Servicios diferenciales para personas con discapacidad y sus cuidadores(as) en el marco del programa En casa sin violencias.

En suma, las anteriores medidas de protección jurídica de las personas con discapacidad vigentes en el Estado colombiano durante la pandemia por la Covid-19 
permiten exponer una serie de recomendaciones que, a juicio de los autores, podrían acentuar la garantía de sus derechos.

\section{RECOMENDACIONES PARA LA PROTECCIÓN JURÍDICA DE LA PERSONA CON DISCAPACIDAD EN ÉPOCA DE PANDEMIA}

De conformidad con el análisis realizado en el acápite anterior se logra evidenciar, por un lado, que las personas con discapacidad se encuentran dentro de los grupos poblacionales con mayor riesgo de contagio y, a su vez, mayor afectación económica, laboral y educativa como consecuencia de la pandemia. Por otro lado, se refirieron las medidas tomadas por el Gobierno nacional con relación a esta población. Por último, se resalta la labor local que ha aunado esfuerzos en cuanto a la protección de las personas con discapacidad en Colombia durante la época de pandemia. Sin embargo, es menester recordar que, pese a que el Gobierno nacional ha emitido un sinnúmero de directrices (decretos, circulares, acuerdos) con el objetivo de mitigar las consecuencias de la Covid-19, las menciones frente a medidas concretas relacionadas con la población con discapacidad son muy reducidas y se han enfocado en temas de salud, dejando de lado aspectos como el laboral o educativo.

El anterior escenario ha sido el preferente en la mayor parte de países del mundo. Por ello, como se refirió anteriormente, la relatora especial sobre los derechos de personas con discapacidad de la ONU ha manifestado su preocupación y, a su vez, ha planteado algunas recomendaciones para tener en cuenta por parte de los Estados miembros de la Convención sobre los derechos de las personas con discapacidad, con el objetivo de garantizar de manera efectiva sus derechos durante la época de pandemia.

Así pues, se pasará a plasmar algunas recomendaciones que podría tener en cuenta el Gobierno colombiano con el fin de salvaguardar a las personas con discapacidad, reducir el contacto y el riesgo de contaminación. Con fundamento en las recomendaciones planteadas por la relatora especial sobre los derechos de personas con discapacidad de la ONU (Oficina del Alto Comisionado de DDHH - ONU, 2020), el Estado colombiano asuma estas sugerencias:

- Es necesario que, desde las entidades territoriales, se incorporen estrategias que permitan implementar el trabajo en casa o trabajo virtual para las personas en condición de discapacidad, así como sus familiares y cuidadores.

- Con el aumento de las cifras de desempleo, es importante generar apoyos económicos adicionales que permitan reducir el riesgo de pobreza o mayor vulnerabilidad para este grupo poblacional.

- Con el fin de enfrentar la pandemia, es de vital importancia que la información referente a la prevención, atención y contención del virus sea accesible para todo el 
mundo, lo que incluye que toda la información debe estar disponible, por ejemplo, en lengua de señas, utilización de subtítulos, mensajes de texto, lectura fácil y lenguaje sencillo.

- Por último, y que se considera de gran importancia para Colombia, es necesario que las organizaciones, fundaciones y demás entidades defensoras de los derechos de las personas con discapacidad se involucren activamente en todas las estrategias y herramientas implementadas.

Frente a este último aspecto se recomienda, por ejemplo, que desde las diferentes entidades territoriales en Colombia (sean municipios, distritos o departamentos), se permita la participación activa (a modo de órganos consultivos) del Consejo para la Inclusión de la discapacidad (creado a través del Decreto 2177 de 2017), así como de los líderes o representantes de los diferentes tipos de discapacidad en cada territorio, de modo que puedan aportar en la creación de planes, programas y estrategias que permitan amparar a este grupo poblacional durante la época de pandemia que, como se ha visto, genera un entorno de mayor vulnerabilidad para las personas en condición de discapacidad.

Por su parte, atendiendo a las sugerencias realizadas desde la Comisión Económica para América Latina y el Caribe (2020), se recomienda:

- El Estado colombiano deberá garantizar que las medidas tomadas para enfrentar la crisis, así como las medidas sanitarias, incorporen un enfoque diferencial que incluya a la discapacidad. Hasta el momento, esto no se ha vislumbrado de manera clara frente a las medidas tomadas por el Gobierno nacional.

- Asegurar la continuidad del trabajo, la educación y la prestación de servicios de salud (como rehabilitación, terapias, entre otros) para las personas con discapacidad a través del uso de tecnologías de la información y las comunicaciones (TIC).

- Es importante garantizar y proveer un apoyo psicosocial a las personas con discapacidad y sus cuidadores(as), así como potenciar las redes de apoyo.

- Flexibilizar las restricciones a la circulación en la vía pública para personas con discapacidad y considerar la posibilidad de establecer horarios de atención diferenciados en los comercios y bancos para personas con discapacidad.

- Se deberá mantener una base de datos actualizada que permita determinar, desde los diferentes territorios, los impactos diferenciados de la pandemia sobre determinados grupos poblacionales, incluidas las personas con discapacidad.

- Finalmente, de organismos internacionales como Human Rights Watch (2020), se puede agregar: 
- Frente a las medidas implementadas por los Gobiernos locales y nacionales, es necesario desarrollar estrategias de prevención y control de la pandemia que atiendan a las necesidades especiales de la discapacidad. Se deberá tener en cuenta, por ejemplo, que una medida tan sencilla como el lavado constante de manos no es tan fácil de incorporar para aquella persona en condición de discapacidad que no puede hacerlo sola y requiere de apoyo constante.

- En el caso de aquellas personas con discapacidad que se encuentren en instituciones o centro cerrados, como por ejemplo centros de rehabilitación o internados (especialmente frente a niños, niñas o adolescente [NNA]), los Gobiernos deberían incorporar las medidas necesarias para su traslado seguro fuera dichos establecimientos. Se recomienda que, en la medida de lo posible, puedan regresar con sus familias.

- En aquellos países donde se han suspendido las clases presenciales y se ha pasado a un modelo de educación virtual, es menester tener presente que los NNA con diferentes discapacidades pueden quedar excluidos si la instrucción educativa no adapta el modelo en línea de modo que pueda ser accesible para todos(as).

Frente a la educación en línea, en Colombia se ha planteado una problemática que afecta a NNA en todo el país: el acceso a internet. Por ello, es necesario que el Gobierno asegure que los alumnos que no tienen acceso a internet puedan contar con materiales y planes de clases accesibles.

- Es necesario que, desde los diferentes niveles gubernamentales, se realice una evaluación periódica de las medidas adoptadas, de modo que se puedan cerciorar que las políticas sean acordes a sus necesidades.

Las anteriores son las sugerencias que consideramos, podrían garantizar el aseguramiento de los objetivos de los lineamientos del Ministerio de Salud y Protección Social (2020), donde, por fortuna, se extrae la base jurídica suficiente que exalta la pretensión garantista y proteccionista de la persona con discapacidad en Colombia. Esta situación abre la puerta para que en futuras investigaciones - seguramente en una época de pospandemia - se permita una medición material de la efectividad de las medidas jurídicas de protección adoptadas en el país.

\section{CONCLUSIONES}

El virus SARS-CoV-2, pese a su impacto sin precedentes en el mundo, ha sido un detonante de cambios a todo nivel, con lo que se ha identificado la necesidad de un cuerpo normativo que estabilice el alto grado de riesgo que representa para las personas con discapacidad. Este contexto es motivo suficiente para la expedición de los lineamientos del Ministerio de Salud (2020), así como del aparato normativo 
vigente que, pese a ser garantista y ajustado a un modelo social de la discapacidad, puede mejorar.

Lo anterior se debe a que el virus ha aumentado el riesgo de vulneración de los derechos de la persona con discapacidad, principalmente debido a las condiciones propias de su vida y el medio de una pandemia. Así, pese a que se pudo identificar la existencia de una base jurídica sólida y proteccionista en Colombia, no deja de persistir la necesidad de una prevención y aseguramiento de la prestación de servicios.

Estas conclusiones surgen a partir del análisis de las medidas de protección jurídica vistas, de donde se deduce que, en época de pandemia, el Estado colombiano ha intentado ajustarse a los lineamientos de la Organización de las Naciones Unidas y ha intentado mantener la garantía de los derechos de manera equitativa y justa.

No obstante los avances, se debe mencionar que pese a que las medidas tomadas por el Gobierno nacional durante los últimos meses para atender la emergencia ocasionada por la Covid-19 han sido numerosas, son muy reducidas las relativas a la protección concreta de las personas con discapacidad durante la época de pandemia.

En este escenario es claro que aún existe una serie de recomendaciones elevadas por actores como la Oficina del Alto Comisionado de los Derechos Humanos (ONU, 2020), la Comisión Económica para América Latina y el Caribe (2020) u organismos internacionales como Human Rights Watch (2020) que se adaptan a los lineamientos del Ministerio de Salud (2020). Todas estas medidas podrían lograr un punto de estabilidad en la capacidad de hacer frente efectivo a la situación por la que atraviesa el planeta, la cual afecta especialmente a los grupos vulnerables de la sociedad como lo son las personas en condición de discapacidad.

Se encuentra, entonces, que las recomendaciones parten de una prevención, control y seguimiento que pretende la garantía y estabilidad de los derechos en riesgo de la persona con discapacidad, en vigencia del modelo social al que se ha adherido Colombia, pues es claro que el esquema busca atenuar las desventajas de la persona en relación con la sociedad a la que pertenece en medio de una crisis.

\section{REFERENCIAS}

Asamblea Nacional Constituyente. (1991, 20 de julio). Constitución Política de Colombia. Gaceta Constitucional n. ${ }^{\circ}$ 116. http://www.secretariasenado.gov.co/senado/basedoc/constitucion_ politica_1991.html

Asociación Síndrome de Down de la República Argentina (s.f.). Cómo debe decirse: discapacitado, persona con discapacidad o con capacidades diferentes. https://www.asdra.org.ar/destacados/como-se-dicediscapacitado-persona-con-discapacidad-o-con-capacidades-diferentes/

BBC. (2020). Covid-19 a mayo 2020. https://www.bbc.com/mundo/noticias-51705060

Comisión Económica para América Latina y el Caribe de la Organización de Naciones Unidas, Cepal (2020). Personas con discapacidad ante la enfermedad por coronavirus (Covid-19) en América Latina 
y el Caribe: situación y orientaciones. https://repositorio.cepal.org/bitstream/handle/1 1362/45491/1/ S2000300_es.pdf

Congreso de la República de Colombia. (2013, 27 de febrero). Ley Estatutaria 1618 de 2013. Por medio de la cual se establecen las disposiciones para garantizar el pleno ejercicio de los derechos de las personas con discapacidad. Diario Oficial n. ${ }^{\circ}$ 48.717. https://www.redjurista.com/Documents/ley_1618_de_2013_ congreso_de_la_republica.aspx\#/

Congreso Europeo sobre las Personas con Discapacidad (2002). La declaración de Madrid "no discriminación más acción positiva es igual a inclusión social". http://www.ub.edu/integracio/docs/normativa/ internacional/Declaracio-Madrid.pdf

Corte Constitucional, Sala Plena. (2018, 10 de mayo). Sentencia SU-040/18. (Cristina Pardo Schlesinger, M.P.). https://www.corteconstitucional.gov.co/relatoria/2018/SU040-18.htm

Corte Constitucional, Sala Séptima de Revisión. (2019, 25 de junio). Sentencia T-286/19. (Cristina Pardo Schlesinger, M.P.). https://www.corteconstitucional.gov.co/relatoria/2019/T-286-19.htm

Corte Constitucional, Sala Quinta de Revisión. (2017, 19 de mayo). Sentencia T-340/17. (Gloria Stella Ortiz Delgado, M.P.). https://www.corteconstitucional.gov.co/relatoria/2017/T-340-17.htm

Presidencia de la República de Colombia. (2020, 17 de marzo). Decreto 417 de 2020. Diario oficial n. ${ }^{\circ}$ 51.259. http://www.suin-juriscol.gov.co/viewDocument.asp?ruta=Decretos/30038962

Presidencia de la República de Colombia. (2017, 22 de diciembre). Decreto 2177 de 2017. Diario oficial n. 50.455. https://www.icbf.gov.co/cargues/avance/docs/decreto_2177_2017.htm

Gómez, N. E., Restrepo, D. A., Gañan, J. y Cardona, D. (2018). La discapacidad desde los enfoques de derechos y capacidades y su relación con la salud pública. Revista Gerencia y Políticas de Salud, 17(35). https://doi.org/10.11144/Javeriana.rgps17-35.dedc

Human Rights Watch. (2020). Proteger los derechos de las personas con discapacidad ante el Covid-19. https:// www.hrw.org/es/news/2020/03/26/proteger-los-derechos-de-las-personas-con-discapacidad-anteel-covid-19

Kenneth, I. (2005). Toward the necessary universalizing of a disability policy. The Milbank Quarterly, 67, 401-428. https://doi.org/10.1111/j.1468-0009.2005.00436.x

Ministerio de Salud y del Interior. (2020). Circular 015. https:/www.minsalud.gov.co/sites/rid/Lists/ BibliotecaDigital/RIDE/DE/DIJ/circular-015-de-2020-covid-19-etnicos-salud-interior.pdf

Ministerio de Salud y Protección Social. (2021). Coronavirus (Covid-19) reportes y tableros de control. https://www.minsalud.gov.co/salud/publica/PET/Paginas/Covid-19_copia.aspx

Ministerio de Salud y Protección Social. (2020). Circular 018. https://www.minsalud.gov.co/sites/rid/ Lists/BibliotecaDigital/RIDE/DE/DIJ/circular-0018-de-2020.pdf

Ministerio de Salud y Protección Social. (2020). Circular 011. https://www.minsalud.gov.co/sites/rid/ Lists/BibliotecaDigital/RIDE/VS/circular-externa-1 1-de-2020.pdf

Ministerio de Salud y Protección Social. (2020). Circular 05. https://www.minsalud.gov.co/sites/rid/Lists/ BibliotecaDigital/RIDE/DE/DIJ/resolucion-385-de-2020.pdf

Ministerio de Salud y Protección Social (2020). Lineamientos de prevención del contagio por Covid-19 y atención en salud para las personas con discapacidad, sus familias, las personas cuidadoras y actores del sector salud. https://www.minsalud.gov.co/sites/rid/Lists/BibliotecaDigital/RIDE/DE/ PS/asif13-personas-con-discapacidad.covid-19.pdf 
Ministerio de Salud y Protección Social. (2020). Resolución 470. https://www.minsalud.gov.co/sites/ rid/Lists/BibliotecaDigital/RIDE/DE/DIJ/resolucion-470-de-2020.pdf

Ministerio de Salud y Protección Social. (2020). Resolución 464. https://www.minsalud.gov.co/sites/ rid/Lists/BibliotecaDigital/RIDE/DE/DIJ/resolucion-464-de-2020.pdf

Ministerio de Salud y Protección Social. (2020). Resolución 385. https://www.minsalud.gov.co/sites/ rid/Lists/BibliotecaDigital/RIDE/DE/DIJ/resolucion-385-de-2020.pdf

Ministerio de Salud y Protección Social. (2020). Resolución 380. https://www.minsalud.gov.co/sites/ rid/Lists/BibliotecaDigital/RIDE/DE/DIJ/resolucion-380-de-2020.pdf

Ministerio de Salud y Protección Social. (2020). En Informe Covid-19 a mayo 2020: https://www. minsalud.gov.co/portada-covid-19.html

Oficina del Alto Comisionado de DDHH-ONU (2020). HCHR. https://www.hchr.org.co/index.php/ informacion-publica/comunicados-de-prensa/comunicados-del-alto-comisionado-en-elmundo/9157-covid-19-quien-protege-a-las-personas-con-discapacidad-alerta-experta-de-la-onu

Organización de las Naciones Unidas, ONU (2020). Las personas con discapacidad no pueden ser aún más discriminadas a causa del coronavirus. https://www.un.org/development/desa/es/news/social/brief-ondisability.html

Organización de las Naciones Unidas, ONU (2015). Objetivo 10 reducción de las desigualdades. https://www. un.org/sustainabledevelopment/es/inequality/

Organización de las Naciones Unidas, ONU (2006). Convención Internacional sobre los Derechos de las Personas con Discapacidad. https://www.ohchr.org/Documents/ProfessionalInterest/crpd_SP.pdf

Organización Mundial de la Salud, OMS (2011). World report on disability. https:/www.who.int/disabilities/ world_report/2011/report/en/

Organización Mundial de la Salud, OPS (2020). Consideraciones relativas a la discapacidad durante el brote del Covid-19. World Healt Organization. https://iris.paho.org/bitstream/handle/10665.2/52026/ OPSNMHCOVID19200009_spa.pdf?sequence $=5$ EisAllowed $=\mathrm{y}$

Seco, J. M. (2015). De la igualdad formal a la igualdad material. Cuestiones previas y problemas a revisar. Revista Derechos y Libertades, 36, 55-89. https://doi.org/10.14679/1037 